\title{
Conservation gains through HCVF assessments in Bosnia-Herzegovina and Romania
}

\begin{abstract}
This paper analyses the conservation gains through High Conservation Value Forest (HCVF) assessments in two South-East European countries (Bosnia-Herzegovina and Romania). These are based on the review of the Draft Forest Stewardship Council (FSC) National Standards and HCVF Manuals and the results of the certification process of seven forest management units in the two countries. The review indicates that the application of Principle 9 (High Conservation Value Forests) and Criterion 6.4 of the FSC in Bosnia-Herzegovina and Romania was influenced by the size and nature of tenure (i.e., public or non-public land), rather than geographic location per se. The study also revealed that the assessment of HCVF has, for the first time, raised the question of conservation of cultural, historical and religious values as well as the sustainable management of those forests relevant for the basic needs of communities. These are values not currently covered at the present by the national conservation legislation in either of these two countries. Findings of this study in both countries demonstrates that there are certain conservation gains as a result of the HCVF assessment, especially related to ecosystem services, prevention of soil erosion and conservation of threatened, endangered and endemic species.
\end{abstract}

Keyword: Bosnia-Herzegovina, Biodiversity, Forest Stewardship Council, High Conservation Value Forests, Romania 